\title{
Uso de polímeros em formulações para preservação de Pectobacterium atrosepticum e Ralstonia solanacearum
}

\author{
Andréia Iraci Tumelero ${ }^{1} \&$ Norimar D'Ávila Denardin ${ }^{2}$
}

Faculdade de Agronomia e Medicina Veterinária, Universidade de Passo Fundo, CEP 99001-970, Cx. Postal 601, Passo Fundo, RS, e-mail: norimar@upf.tche.br. ${ }^{1}$ Bolsita da Universidade de Passo Fundo. ${ }^{2}$ Profa Dra. da FAMV - Universidade de Passo Fundo.

Autor para correspondência: Norimar D'Ávila Denardin

Data de chegada:17/03/2005. Aceito para publicação em:10/05/2007.

\section{RESUMO}

Tumelero, A.I.; Denardim, N.D. Uso de Polímeros em Formulações para Preservação de Pectobacterium atrosepticum e Ralstonia solanacearum. Summa Phytopathologica, v.34, n.1, p.58-61, 2008

A sobrevivência de Pectobacterium atrosepticum e de Ralstonia solanacearum foi avaliada em veículo à base de goma xantana (GX), um polímero biológico, e de goma xantana acrescida de polivinilpirrolidona (PVP), um polímero sintético. As culturas, após crescimento até $10^{11}$ ufc $\mathrm{mL}^{-1}$ foram injetadas junto a essas formulações e a sobrevivência avaliada em diferentes condições de armazenamento: em temperatura ambiente, em refrigerador $\left(4^{\circ} \mathrm{C}\right)$ e em freezer $\left(-20^{\circ} \mathrm{C}\right)$, por 36 meses. A concentração de células viáveis foi realizada através de diluições seriadas. A patogenicidade foi avaliada em plantas hospedeiras e em iscas. Os resultados permitem observar que a concentração de células viáveis decresceu ao longo do tempo, mantendo-se entre $10^{3}$ e $10^{4} \mathrm{ufc} \mathrm{mL}^{-1}$ ao final de três anos, exceto para a formulação à base de GX e armazenamento à $-20^{\circ} \mathrm{C}$, que se mostrou ineficiente para ambas as bactérias. Conclui-se, que os polímeros avaliados mostraram-se eficientes em preservar e manter as características bioquímicas e fisiológicas das bactérias Pectobacterium atrosepticum e de Ralstonia solanacearum.

Palavras chave: Viabilidade celular, armazenamento, goma xantana, PVP.

\section{ABSTRACT}

Tumelero, A.I.; Denardim, N.D. Formulation with polymers for the Pectobacterium atrosepticum e Ralstonia solanacearum. Summa Phytopathologica, v.34, n.1, p.58-61, 2008

The survival of Pectobacterium atrosepticum and Ralstonia solanacearum was evaluated in biopolymer carrier xanthan gum (GX) and xanthan gum together with polymer synthetic polyvinylpyrrolidone (PVP). The cultures after growing up to $10^{11}$ ufc $\mathrm{mL}^{-1}$ were injected into the plolymers carriers. The survival of the bacteria was evaluated at room temperature, refrigerator $\left(4^{\circ} \mathrm{C}\right)$ and freezer $\left(-20^{\circ} \mathrm{C}\right)$ for 36 months. The evaluation of viability of the preserved bacteria was carried through seriate dilutions using drop method. The pathogenicity was observed in plant hosts and through baits. The results allow observing that the concentration of viable cells decreased along the time mainting to $10^{3}$ and $10^{4} \mathrm{ufc} \mathrm{mL}^{-1}$ for three years with exception, of the formulation to the base of GX and storage the $-20^{\circ} \mathrm{C}$, that was inefficient for preservation of both the tested bacteria. The polymers applied persevering and mainting the characteristic biochemical and physiological of the bacteria showing efficient to preservation.

Additional keywords: Cellular viability, storage, xanthan gum, PVP.

A preservação de bactérias em nitrogênio líquido e/ou liofilizadas são os métodos que mais se destacam para a maioria das linhagens microbianas, por garantir a identidade original da célula, por longos períodos. Porém, nem todos os laboratórios dispõem dos equipamentos necessários para aplicação de tais métodos.

Entre as várias razões para a preservação de bactérias, destacamse pesquisa, ensino, taxonomia e aplicações em diferentes processos industriais, dentre outros. Várias coleções de culturas encontram-se estocadas em bacteriotecas distribuídas pelo mundo, com a função primordial de preservar as características genéticas e morfofisiológicas de coleções microbianas $(1,7$ e 8$)$.

$\mathrm{Na}$ busca de alternativas para a preservação de bactérias torna-se indispensável investigar novos métodos que garantam eficiência e baixo custo de manutenção, o que demanda o desenvolvimento de acondicionadores com propriedades que assegurem a sobrevivência e as características genéticas e físiológicas das bactérias. Nesse sentido, acondicionadores assumem importância, sendo desejável que assegurarem viabilidade das células bacterianas, sejam de fácil de manipulação, atuem como agente protetor e não possuam toxicidade à bactéria. Vários polímeros sintéticos e naturais mostram-se eficientes para preservar bactérias. Objetivando avaliar a eficiência de acondicionadores dessa natureza, foram desenvolvidas formulações a base de polímeros, sendo um deles goma xantana (GX), um biopolímero extraído da bactéria Xanthomonas campestris pv. campestris, e outro polivinilpirrolidona (PVP), um polímero sintético.

$\mathrm{Na}$ elaboração dos acondicionadores, prepararam-se formulações à base de goma xantana (GX) a 1\%, e Polivinilpirrolidona (PVP) a $1,5 \%$. Foram transferidos $4 \mathrm{~mL}$ de cada formulação para frascos esterilizados com capacidade para $10 \mathrm{~mL}$, os quais foram esterilizados em autoclave por 20 minutos. 
As bactérias Pectobacterium atrosepticum - Pa (IBSBF - 424) e Ralstonia solanacearum - Rs (IBSBF-1232), obtidas no Instituto Biológico, Centro Experimental de Campinas, São Paulo, foram reconstituídas a partir do estado liofilizado e cultivadas em meio de cultura 523 de Kado \& Hesket (3) por 24 e 48 horas, respectivamente. Após o crescimento efetuou-se coloração de Gram, testes bioquímicos e fisiológicos e de patogenicidade. Para $R$. solanacearum, utilizou-se o meio TZC de Kelman (5) o qual possibilita identificar colônias virulentas. Frutos de pimentão verde (Capsicum annum) e rodelas de tubérculos de batata (Solanum tuberososum L.) foram utilizados como meio parcialmente seletivo de $\mathrm{Pa}(3,4,9$, e 10$)$.

Para produção de células de cada bactéria, procedeu-se o cultivo em meio líquido 523 de Kado \& Hesket (3), por 24 horas. A seguir, realizou-se novo cultivo tomando-se alíquotas de $5 \mathrm{~mL}$ dessa suspensão bacteriana e reinoculando-se em meio líquido 523 Kado \& Hesket, por 36 horas, para obtenção de caldo com concentração de $10^{11}$ unidades formadoras de colônia por $\mathrm{mL}$ (ufc), o qual foi distribuído, assepticamente, em alíquotas de $2 \mathrm{~mL}$ por frasco contendo $4 \mathrm{~mL}$ das diferentes formulações à base de polímeros. Após a realização das formulações para as preservações das bactérias, fez-se a contagem das ufc $\mathrm{mL}^{-1}$, considerando-se como primeira contagem o tempo zero. A seguir os frascos foram vedados, devidamente rotulados e armazenados à temperatura ambiente, em refrigerador $\left(4^{\circ} \mathrm{C}\right)$ e em freezer $\left(-20^{\circ} \mathrm{C}\right)$. Os tratamentos foram: temperatura ambiente (GX-A; GX+PVP-A), refrigerador (GX-G; GX+PVP-G) e freezer (GX-F; GX+PVP-F). As avaliações foram realizadas mensalmente, durante os primeiros 12 meses e anualmente nos dois anos seguintes.

O método empregado para a contagem das ufc $\mathrm{mL}^{-1}$ foi o de diluição seriada em meio 523 de Kado \& Hesket, conforme técnica de Miles \& Misra (5). Foram efetuadas nove avaliações por diluição de cada uma das formulações, ou seja, três placas de Petri setoriadas em quatro, por diluição, com três gotas de $10 \mu \mathrm{L}$ em cada setor, em cada placa e para cada diluição. Dessa forma, foram realizadas três repetições de cada um dos dois tipos de formulação, sendo considerado para a avaliação 27 gotas por época para cada repetição. As médias foram transformadas em logaritmo de base 10 para avaliar o comportamento ao longo do tempo.

A patogenicidade das bactérias nos diferentes tratamentos foi avaliada em plantas de batata e de tomate (Licopersicon esculentum), bem como através de iscas de pimentão e de batata. A observação dos sintomas característicos, para cada doença, foi avaliada visualmente a partir dos primeiros sintomas da doença.

Os resultados referentes à sobrevivência da bactéria $R$. solanacearum expressas em ufc $\mathrm{mL}^{-1}$, para cada formulação e condições de armazenamento estão apresentadas na Figura 1. Durante o período de avaliação verificou-se decréscimo na concentração de células viáveis em ambas as formulações e condições de armazenamento. A concentração inicial de células de $R$. solanacearum foi de $10^{7}$ ufc $\mathrm{mL}^{-1}$. Após 12 meses (Figura 1), decresceu para $10^{5}$ ufc $\mathrm{mL}^{-1}$ para o tratamento $\mathrm{GX}+\mathrm{PVPF}$, e $10^{4}$ ufc $\mathrm{mL}^{-1}$ para os demais tratamentos, exceto para o tratamento GXF que a partir do sexto mês, perdeu a viabilidade celular.

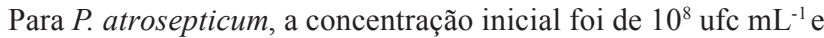
após 12 meses, decresceu, atingindo concentração média em torno de $10^{4}$ ufc $\mathrm{mL}^{-1}$, para todos os tratamentos, exceto para GXF, que apresentou morte celular aos 30 dias (Figura 2). Na formulação GX+PVPF, a sobrevivência da bactéria foi observada até dois anos, mantendo uma concentração de $10^{4} \mathrm{ufc} \mathrm{mL}^{-1}$, e aos três anos, apresentou o mesmo comportamento que a preservação em GXF (Figura 2). Esse resultado é semelhante ao que ocorreu para $R$. solanacearum.

Aos três anos, observou-se que não houve diferença entre os tratamentos que apresentaram células viáveis, mantendo a concentração em torno de $10^{3} \mathrm{ufc} \mathrm{mL}^{-1}$. Resultados semelhantes foram verificados por Denardin (2) que avaliou os mesmos polímeros para acondicionar células de Bradyrhizobium elkani, constatando que as concentração de células viáveis, ao longo de oito meses de armazenamento diminuíram. De acordo com a mesma autora, o inóculo inicial para o estudo foi de $10^{10} \mathrm{ufc} \mathrm{mL}^{-1}$, aos oito meses de armazenamento, em temperatura ambiente, permaneceu na faixa de

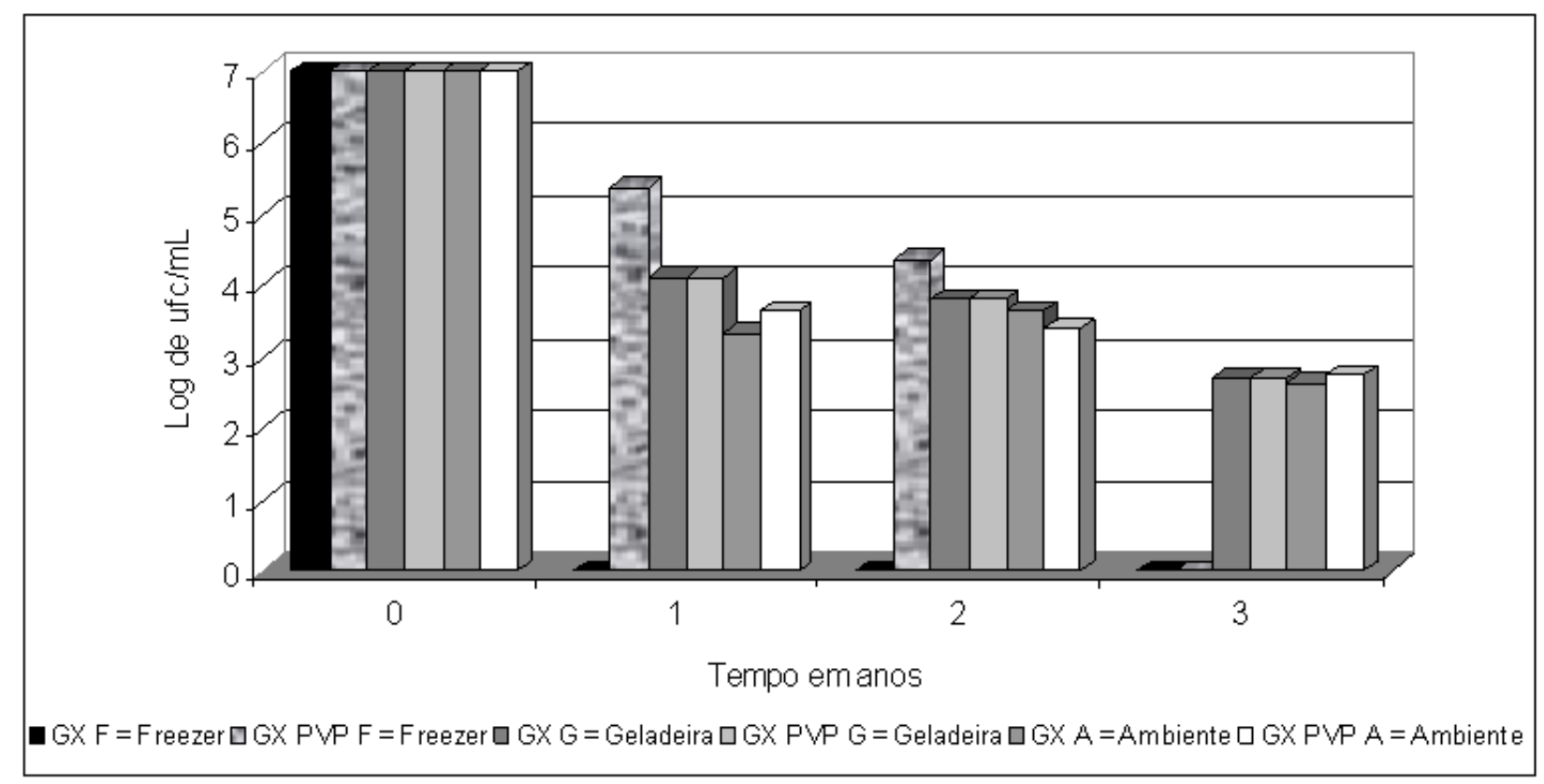

Figura 1. Unidades formadoras de colônias (UFC) de Ralstonia solanacearum, ao longo de três anos, acondicionadas em diferentes formulações e em diferentes condições de armazenamento. 


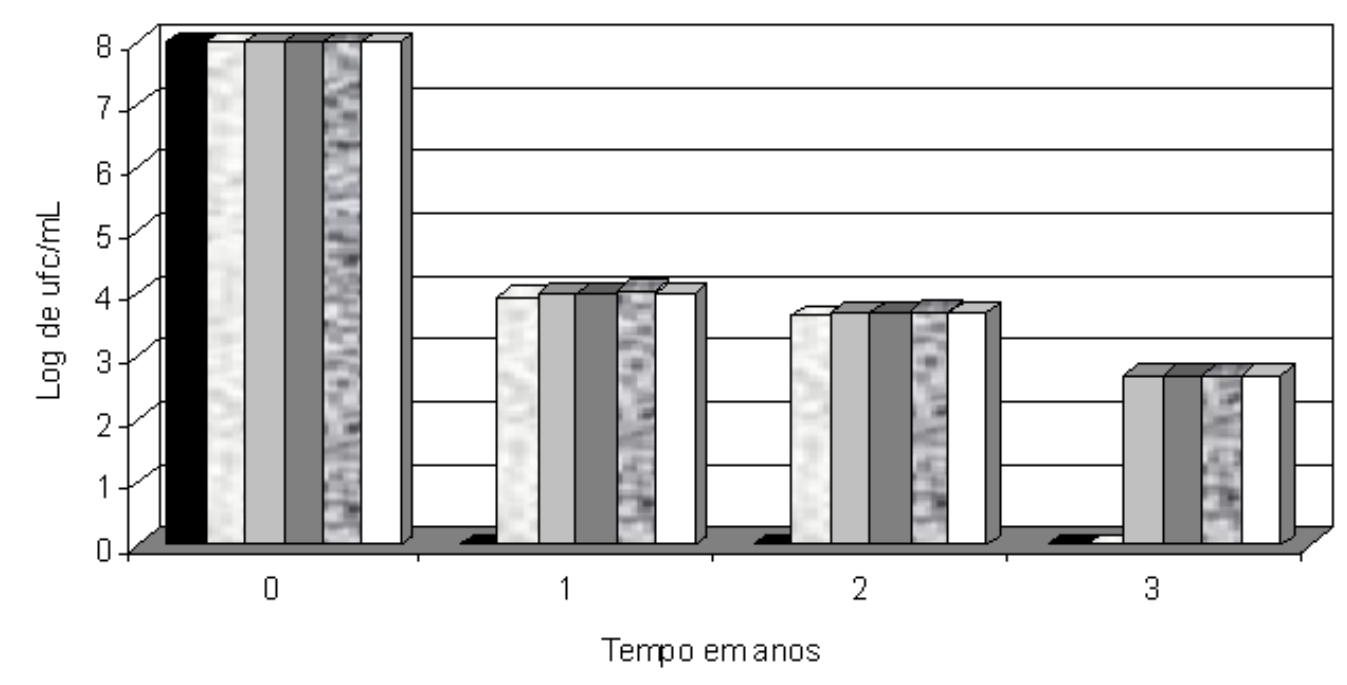

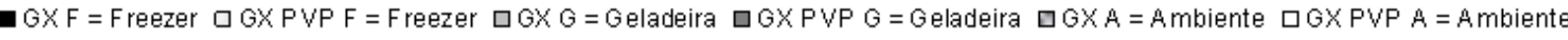

Figura 2. Médias das unidades formadoras de colônias (UFC) de Pectobacterium atrossepticum ,ao longo de três anos, acondicionadas em diferentes formulações e em diferentes condições de armazenamento.

$10^{9} \mathrm{ufc} \mathrm{mL}^{-1}$. As bactérias testadas no presente estudo, após 12 meses,

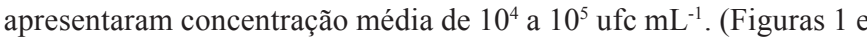
2). Esses valores podem estar relacionados com a concentração inicial, pois possivelmente, se o ensaio tivesse partido de concentração inicial maior, a média de ufc $\mathrm{mL}^{-1}$, ao longo do tempo, teria se mantido em nível superior.

Takatsu (11) através do método de dessecação preservou várias bactérias fitopatogênicas em tiras de papel filtro, por mais de três anos. No entanto, para $R$. solanacearum e espécies do grupo de Pectobacterium carotovorum, o limite seguro de preservação foi de 18 meses. $\mathrm{O}$ autor ressalta que esse método é relativamente simples e econômico e possibilita com facilidade o intercâmbio de culturas bacterianas entre pesquisadores. Para o presente estudo, verificouse que ao fim de três anos, para $R$. solanacearum, preservada em GX + PVPF, houve morte celular. O limite de preservação para este tratamento foi de dois anos, com concentração de $10^{4} \mathrm{ufc} \mathrm{mL}$ ${ }^{1}$. Nos demais tratamentos, a concentração de células bacterianas permaneceu em torno de $10^{3}$ ufc $\mathrm{mL}^{-1}$ (Figuras 1 e 2). O comportamento de $P$. atrossepticum foi o mesmo verificado para $R$. solanacearum, sob o mesmo tratamento e condições de armazenamento (Figuras 1 e 2).

Ralstonia solanacearum é uma bactéria que facilmente perde a virulência. Por isso, existe grande dificuldade para estabelecer um método que mantenha a capacidade infectiva e de virulência dessa bactéria (6 e 9). A preservação de isolados em água e em óleo mineral foi estudada por Takatsu (11) durante, aproximadamente, um ano, em temperatura ambiente $\left(25 \mathrm{a} 30^{\circ} \mathrm{C}\right)$. $\mathrm{O}$ autor observou que quanto mais baixa a temperatura, maior e mais rápida as taxas de transformação em formas avirulentas.

Nos testes de patogenicidade, verificou-se canela preta na haste de batateira, podridão mole em tubérculos de batata e em frutos de pimentão, típica de pectobactérias, como também foi observado murchadeira no tomateiro, respectivamente, para $P$. atrossepticum e $R$. solanacearum, indicando que as mesmas mantiveram suas características inalteradas durante o período de armazenamento. A liofilização seria o método mais seguro para a preservação de bactérias, mesmo que após o tratamento $50 \%$ das células morrem, pois esse processo garante as características genéticas das bactérias. Entretanto, a liofilização, ainda para alguns laboratórios é ainda um procedimento inviável, em decorrência da inacessibilidade ao equipamento.

Nesse sentido considera-se que as formulações desenvolvidas mostram-se eficientes na conservação das características fisiológicas das bactérias em estudo. Essas formulações apresentam, ainda, praticidade e economia, já que não demandam renovação constante das células e, além disso, permite armazenamento em temperatura ambiente. Em vista da potencialidade dos polímeros em acondicionar as bactérias, $P$. atrossepticum e $R$. solanacearum, é aconselhável estender esse método para outros gêneros. Conclui-se, desse modo, que as formulações à base de polímeros, para preservar células bacterianas, foram satisfatórias nas diferentes condições de armazenamento para ambas as bactérias avaliadas.

\section{REFERÊNCIAS BIBLIOGRÁFICAS}

1. Crist, D. K.; Wyza, R. E.; Mills, K. K.; Bauer, W.D.; Evans, W. R. Preservation of Rhizobium viability and symbiotic by suspension in water. Appl. Environ. Microbiol., v.47, p.595-600, 1984.

2. Denardin, N. D. \& Freire J. R. J. Assessment of polymers for the formulation of legume inoculants. World Journal of Microbiology end biotechnology. Passo Fundo. v.16, n.3, p 215-217, 2000

3. Kado, C.J. \& Heskett, M.G. Selective media for isolation of Agrobacterium, Corynebacterium, Erwinia, Pseudomonas and Xanthomonas. Phytopathology. Worcester, v.60, n.6, p.969-976, 1970.

4. Kelman, A. The relationship of Pseudomonas solanacearum to colony appearance on a tetrazolium. Phytopathology. v.44, p. 693-695, 1954.

5. Miles A. A. \& Misra S.S. The estimation of the bacterial power ofthe blod. Journal of Hygiene, Cambridge, v. 38, p.732-749, 1938.

6. Schaad, N. W. Laboratory guide for identification of plant pathogenic bacteria. 2 ed. St. Paul: 1988, 164p.

7. Silva, L. F. Comparação de métodos de preservação de leveduras de interesse industrial. 1990. Tese (Mestrado). Uni- 
versidade de São Paulo, São Paulo. 151p.

8. Silva, L. F.; Oliveira, M. S. Preservação de culturas de Rizóbios. In: Hungria, M.; Araujo, R. S. Manual de Métodos Empregados em Estudos de Microbiologia Agrícola. Brasília, DF: Embrapa-SPI, 1994. 542p.

9. Silveira, J.R. F., Duarte, V. \& Moraes, M. G. Ocorrência das biovares 1 e 2 de Ralstonia solanacearum em lavouras de batata no
Estado do Rio Grande do Sul. Fitopatologia Brasileira. DF v.27 (5) p. 450-453. 2002

10. Takatsu, A. Erwinias do grupo carotovora no Brasil. Fitopatologia Brasileira, Brasília, v. 8, p. 535-536, 1983.

11. Takatsu, A. Preservação das bactérias fitopatogênicas pelo método de dessecação. Fitopatologia Brasileira, Brasília, v.5 p.461161 , out. 1980 . 